\title{
Metodologia de Baixo Custo para Registro de Imagens do Arco Voltaico de Soldagem
}

\author{
Anna Louise Voigt ${ }^{1}$, Tiago Vieira da Cunha ${ }^{1}$, Víctor Vergara Díaz ${ }^{2}$ \\ 1 Universidade Federal de Santa Catarina, Campus Joinville, Joinville, SC, Brasil. \\ 2 Universidad de Antofagasta, Departameto de Ingeniería Mecánica, Campus Coloso, Antofagasta, Chile.
}

Recebido: 14 Ago., 2017

Aceito: 20 Nov., 2017

E-mail: anna.voigt@posgrad.ufsc.br (ALV)
Resumo: Equipamentos que permitem o registro de imagens são importantes ferramentas no estudo dos processos de soldagem. Contudo, câmeras de alta velocidade que permitem a captura de imagens do arco voltaico e dos fenômenos envolvidos, a exemplo da transferência metálica, são limitadas devido ao seu alto custo. Tendo em visto a utilização de câmeras de baixo custo relativo, o presente estudo tem por objetivo avaliar os efeitos dos parâmetros de exposição no registro do arco voltaico, sendo este, semelhante ao que se observa através da máscara de soldagem. Logo, analisou-se os efeitos da abertura do diafragma, tempo de exposição e sensibilidade ISO. Além destes parâmetros, foram empregados filtros na lente da câmera a fim de melhorar a qualidade das imagens. Por fim, aplicou-se o conhecimento adquirido no registro do processo TIG com alimentação de arame frio, sendo possível a visualização das gotas sendo transferidas bem como da poça de fusão.

Palavras-chave: Fotografia do arco; Auxílio visual; Imagens do arco.

\section{Low Cost Methodology for Images Recording of Arc Welding}

\begin{abstract}
Equipment that allows images recording are important tools in study of welding processes. However, high-speed cameras that allow capture of arc images and phenomena involved, such as metal transfer, are limited due to their high cost. Considering use of low cost cameras, the present study has the objective of evaluating the effects of exposure parameters on the arc recording, which is similar to that observed through the welding mask. Therefore, the effects of diaphragm aperture, shutter speed and ISO sensitivity were analyzed. In addition to these parameters, filters were used on the camera lens in order to improve the quality of the images. Finally, the knowledge acquired in the TIG process registration with cold wire feed was applied, being possible to visualize the droplets being transferred as well as the weld pool.
\end{abstract}

Key-words: Arc photography; Vision system; Arc images.

\section{Introdução}

A demanda por maior produtividade e qualidade nas uniões produzidas pelos processos de soldagem é algo frequente na indústria. Deste modo, a fim de atender a estes propósitos, diversas técnicas de soldagem têm sido constantemente estudadas e desenvolvidas ao longo dos anos. No entanto, o desenvolvimento destas técnicas, ou a obtenção do desempenho operacional almejado, muitas vezes só é possível a partir da compreensão dos fenômenos ocorridos no arco voltaico e/ou na poça de fusão. O que torna necessário o emprego de métodos específicos de aquisição, de modo a permitir uma completa análise dos fenômenos. Neste contexto, câmeras de alta velocidade têm sido empregadas como uma importante ferramenta de análise por pesquisadores da área da tecnologia da soldagem. Entretanto, seu elevado custo de aquisição (na ordem de 50 mil dólares) frequentemente torna-se um impeditivo para a sua obtenção e, consequentemente, utilização por muitos laboratórios de pesquisa.

Assim, o emprego de câmeras convencionais, de relativo baixo custo (da ordem de 2 mil reais), pode constituir-se numa alternativa conveniente àqueles que não dispõem de uma câmera de alta velocidade, sendo assim, uma importante ferramenta de auxílio às análises. Evidentemente, não se espera com estes equipamentos obter a mesma capacidade de análise encontrada com as câmeras de alta velocidade. Todavia, com o emprego destas câmeras convencionais é possível realizar o registro, ainda que limitado, de diversos fenômenos ocorridos na soldagem. Fenômenos como alterações na geometria do arco voltaico ou sua deflexão devido ao sopro magnético, ou seja, tudo aquilo que pode sobte é um artigo publicado em acesso aberto (Open Access) sob a licença Creative Commons Attribution Non-Commerci, que permite uso, distribuição e reprodução em qualquer meio, sem restrições des de que sem fins comerciais e que trabalho original seja corretamente citado. 
ser observado através das lentes das máscaras de soldagem, inclusive alguns modos de transferência metálica, podem ser registrados de forma bastante satisfatória atendendo, assim, muitas das necessidades de pesquisadores. Para tanto, basta empregar uma câmera fotográfica convencional, equipada de filtros específicos, com o adequado ajuste dos parâmetros de exposição.

Desta forma, o presente trabalho tem por objetivo apresentar uma metodologia, baseada no emprego de câmeras fotográficas convencionais de relativo baixo custo, para registro de imagens do arco voltaico de soldagem, discutindo os efeitos dos parâmetros de exposição da câmera, bem como exemplificando a sua utilização no processo GTAW com adição de arame frio.

\section{Materiais e Métodos}

Tendo em vista que o objetivo de obtenção de imagens do arco voltaico proposto neste trabalho consiste em fazer uso de uma metodologia que possibilite o registro daquilo que pode ser visualizado através de uma máscara de soldagem simples, utilizaram-se filtros para câmeras fotográficas com a mesma finalidade dos filtros utilizados em tais máscaras. Estes são chamados filtros de densidade neutra, ou simplesmente "ND", e possuem diversas graduações. Quanto maior o número do filtro ND, maior é o seu escurecimento. Estes filtros podem ser adquiridos em, basicamente, duas versões. Com o diâmetro equivalente ao da lente a ser utilizada ou retangulares que, em geral, são mais versáteis e de menor custo, pois permitem o acoplamento em lentes com diversos diâmetros fazendo-se uso de um adaptador.

A câmera fotográfica utilizada no presente trabalho é do tipo DSLR, que permite o ajuste manual dos parâmetros de exposição, além de permitir a utilização de diferentes lentes. O modelo utilizado é o Rebel T3, sendo um modelo de DSRL simples e de relativo baixo custo, indicada para iniciantes na fotografia profissional.

A maioria dos aspectos relacionados à formação de uma imagem óptica de um objeto se aplica tanto à fotografia analógica quanto à digital. Nestas, a lente está posicionada a frente de uma caixa, ou câmera fotográfica, com uma superfície sensível à luz, que no caso das câmeras analógicas é um filme fotossensível e nas câmeras digitais um sensor fotossensível, normalmente do tipo CCD (Charge Coupled Device) ou CMOS (Complementary Metal Oxide Semiconductor) [1,2]. A luz é impedida de alcançar o filme ou sensor por um obturador até o momento escolhido da exposição (a fotografia de fato). A quantidade de exposição à luz no qual é submetida é frequentemente controlada por uma combinação do tempo que o obturador permanece aberto (tempo de exposição) e o diâmetro do feixe de luz que passa através da lente, este último é alterado por uma abertura, semelhante à íris do olho. Ambos os controles têm uma influência adicional sobre os resultados visuais obtidos na imagem registrada. $\mathrm{O}$ tempo de exposição altera a maneira como os registros de movimento ficam desfocados ou "congelados", por sua vez, a abertura da lente altera a profundidade do assunto que é mostrada em foco ao mesmo tempo [1]. De forma a avaliar os efeitos desses parâmetros na obtenção de imagens do arco voltaico, neste trabalho a câmera fotográfica, na configuração " $\mathrm{A}$ ", foi posicionada a uma distância fixa de $120 \mathrm{~mm}$ entre o eletrodo e a lente, com o arco voltaico posicionado ao longo do eixo central da lente a fim de evitar distorções das imagens, possibilitando, assim, uma menor visualização do perfil do arco voltaico no que diz respeito ao espectro de luz visível. Já nos casos em que o interesse foi o registro da poça de fusão, a configuração "B" foi utilizada. Nesta a câmera fotográfica foi posicionada com uma inclinação de 15으 a fim de permitir uma melhor visualização da poça de fusão. Na Figura 1 é apresentada a bancada de ensaios com os equipamentos e configurações empregadas.

Ambas as configurações permitem apenas uma análise qualitativa das dimensões do arco voltaico, em especial, a configuração "B", visto que a inclinação gera distorções na imagem registrada [3]. As condições empregadas na realização dos ensaios estão descritas na Tabela 1.

Em todos os ensaios realizados a distância eletrodo-peça (DEP) utilizada foi mantida em $4 \mathrm{~mm}$, proporcionando uma arco voltaico de maior dimensões e, assim, permitindo uma melhor avaliação dos parâmetros de regulagem da câmera. Quanto à distância focal da lente, ao se empregar $55 \mathrm{~mm}$ obteve-se uma melhor visualização devido ao zoom sem a necessidade de aproximar demasiadamente a câmera fotográfica do arco voltaico e, portanto, sem expor a mesma às condições inadequadas de operação no que tange a temperatura. 


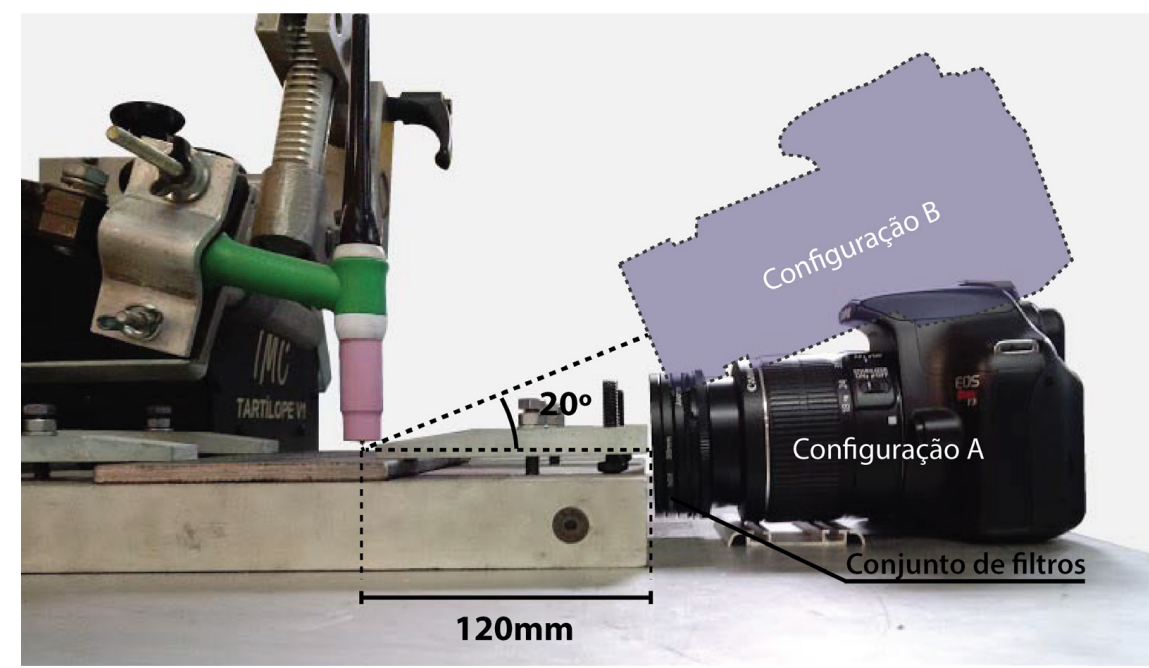

Figura 1. Bancada de ensaios com configuração "A" montada e configuração "B" representada.

Tabela 1. Condições de soldagem utilizadas nos ensaios de registro de imagens do arco voltaico.

\begin{tabular}{cc}
\hline Variável ou parâmetro & Valor \\
Gás de proteção & Argônio Puro \\
Vazão do gás [L/min] & $10 \mathrm{l} / \mathrm{min}$ \\
Diâmetro do eletrodo & $2,4 \mathrm{~mm}$ \\
Tipo do eletrodo & EWTh-2 \\
Ângulo de afiação & $60^{\circ}$ \\
DEP & $4 \mathrm{~mm}$ \\
Comprimento livre do eletrodo & $24 \mathrm{~mm}$ \\
Bocal de cerâmica & $\mathrm{n}^{\circ} 7$ \\
\hline
\end{tabular}

\section{Efeito das Regulagens da Câmera nas Imagens Obtidas}

\subsection{Abertura do diafragma}

O diafragma é composto por uma série de lâminas de metal sobrepostas, permitindo que o tamanho desta abertura seja restringido continuamente a partir do diâmetro total da lente. Uma série de configurações de abertura relativa é mostrada na Figura 2 em uma escala de números conhecidos como números-f. Os números-f indicam o número de vezes que o diâmetro efetivo da abertura se divide na distância focal da lente. Logo, $\mathrm{f} / 2$ significa ajustar um diâmetro de abertura a metade da distância focal; f/4 é um quarto, e assim por diante. Quanto menor for a abertura relativa maior será o número-f, sendo tipicamente na sequência: $f / 2, f / 2.8, f / 4, f / 5.6, f / 8, f / 11, f / 16$ [1].

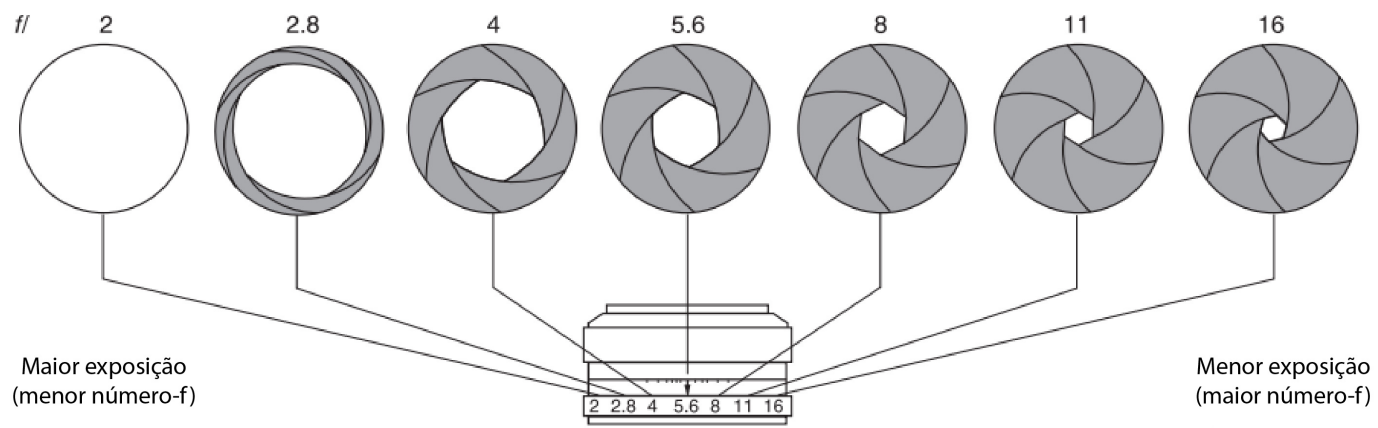

Figura 2. Exemplo de números-f típicos [1]. 
O número-f, e consequentemente a abertura do diafragma, afeta diretamente a profundidade de campo, que pode ser entendida como a faixa na qual os objetos estarão focados. Maiores números-f correspondem a maiores profundidades de campo, como pode ser observado na Figura 3.

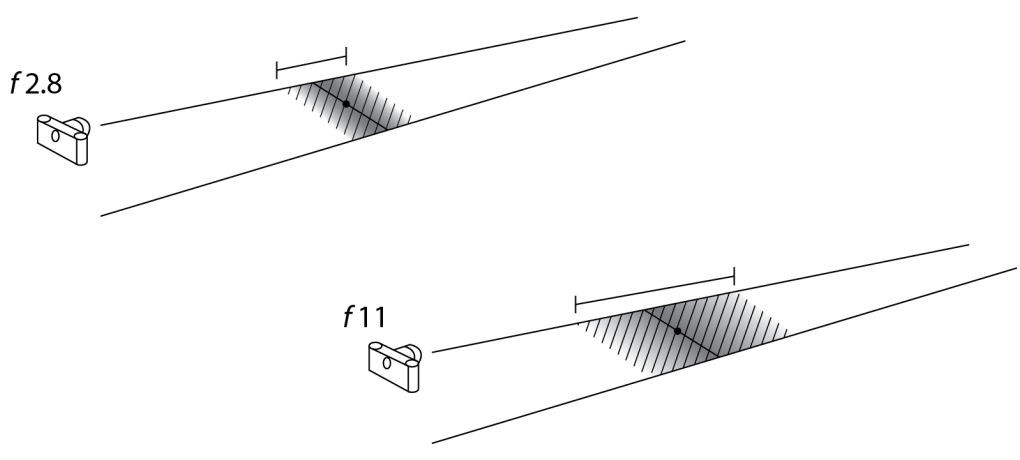

Figura 3. Profundidade de campo ilustrativa para diferentes números-f [1].

No caso da lente 18-55 mm utilizada no presente trabalho, em razão da distancia focal de $55 \mathrm{~mm}$ empregada, a abertura do diafragma poderia ser variada somente entre f/5.6 e f/36. Deste modo, mantendo os demais parâmetros da câmera fixos, realizaram-se registros do arco voltaico estabelecido nas condições da Tabela 1 empregando-se os seguintes valores de abertura do diafragma: f/5.6, 7.1, 9, 11, 16, 18, 22, 29 e 36 . O resultado destes ensaios pode ser visto na Figura 4.
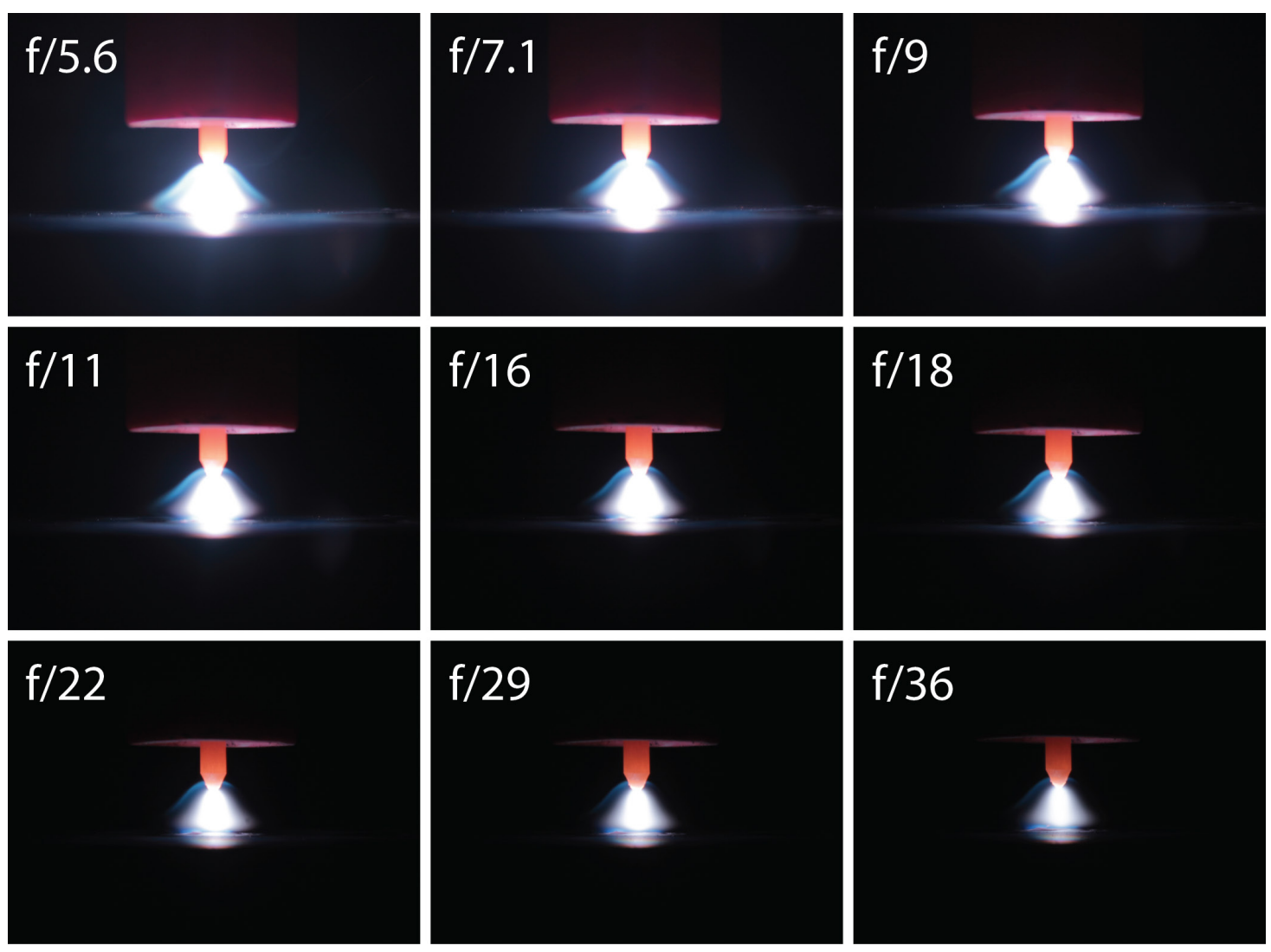

Figura 4. Obtenção de imagens do arco voltaico para diferentes números-f numa mesma configuração de câmera para um tempo de exposição fixo de (1/100)s. 
Conforme esperado, neste é possível observar que um maior número-f e, consequentemente, uma menor abertura, resulta em uma menor entrada de luz para um mesmo tempo de exposição de (1/100)s. Para esta configuração, o ajuste do foco deve ser feito manualmente, e anteriormente ao posicionamento do filtro ND, pois o mesmo impede a visualização do eletrodo. Conforme pode ser observado, na imagem com f/5.6 o eletrodo está desfocado, pois, a regulagem do foco foi realizada manualmente para uma abertura f/36. Isto se deve porque uma maior abertura (menor número f) resulta em uma menor profundidade de campo. Logo, para uma profundidade de campo maior (f/36) o eletrodo se encontra focado, mas ao reduzir o número f, o mesmo deixa de estar na área focada. Portanto, ao utilizar o foco manual, o mesmo deve ser ajustado para o número f a ser utilizado na obtenção da imagem.

Uma menor profundidade de campo pode ser desejável para fotografar retratos, além do menor número-f possibilitar uma maior entrada de luz. O número f da abertura máxima da lente, juntamente com sua distância focal, são gravados na borda da lente. Contudo, para o registro de imagem do arco voltaico, é desejável uma maior profundidade de campo, de modo que o arco e sua periferia estarão focados.

\subsection{Tempo de exposição}

Um dos ajustes que podem ser realizados na câmera a fim de compensar a demasiada luminosidade do arco voltaico é a utilização de maiores velocidades do obturador e, consequentemente, menores tempos de exposição. Contudo, dependendo da energia de soldagem utilizada, visto que a câmera possui velocidade de obturação limitada, a imagem resultante pode ficar completamente saturada no que diz respeito à luz. Este aspecto evidencia a importância da utilização de filtros ND, que reduzem a incidência de luz significativamente, possibilitando a obtenção de imagens de processos com maior energia de soldagem. Entretanto, se os filtros não forem corretamente aplicados, podem exigir tempos de exposição altos, resultando em imagens de aspecto "borrado", devido a isso, devem-se evitar tempos de exposição inferiores à (1/50)s. Na Figura 5 são apresentadas imagens do arco voltaico obtidas com diferentes aberturas do diafragma e com dois tempos de exposição diferentes de (1/100) e (1/200)s.
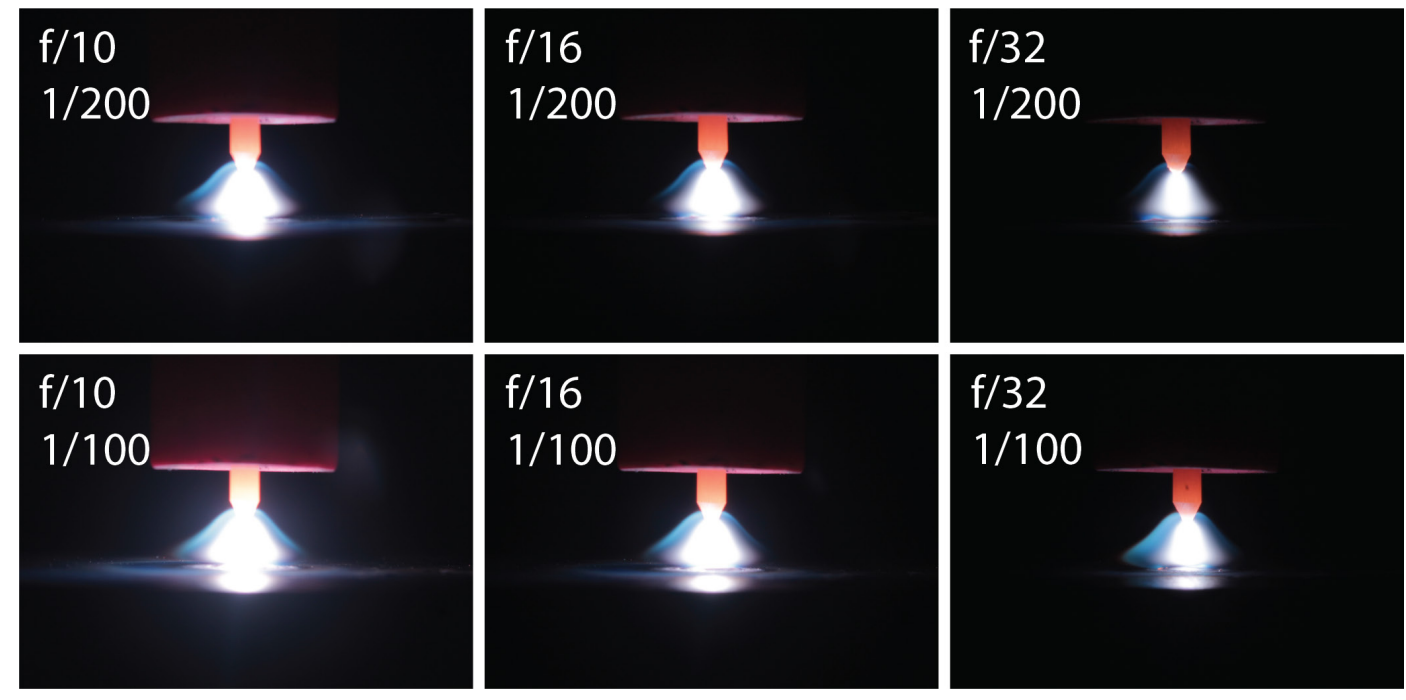

Figura 5. Imagens do arco voltaico obtidas com diferentes aberturas do diafragma e com tempos de exposição de $(1 / 100)$ e $(1 / 200)$ s.

Com base nestes resultados, percebe-se a necessidade de um equilíbrio entre o ajuste de abertura do diafragma e tempo de exposição. Isto, para que a imagem obtida não fique saturada (com demasiada luminosidade), ou muito escura, deixando de representar o que se deseja. Por exemplo, se o objeto de interesse é o eletrodo, menores tempos de exposição irão permitem uma melhor visualização do mesmo em detrimento da visualização do arco voltaico. Esta configuração também se torna interessante para aplicações onde o interesse é a visualização da transferência metálica (quando realizada numa taxa possível de ser visualizada como no caso do processo TIG). 


\subsection{Sensibilidade ISO}

ISO é a sensibilidade do sensor à luz. Se o ISO é aumentado, a sensibilidade do sensor aumenta e, com menos luz, é possível captar a cena desejada. Com um ISO baixo pouca luz é captada e, portanto, quase não apresenta ruído e os contornos ficam mais nítidos. O emprego de elevados valores de ISO resulta em imagens com ruído perceptível, prejudicando a nitidez dos detalhes. Com o intuito de avaliar o efeito da sensibilidade ISO nas imagens do arco voltaico, manteve-se constante o ajuste da abertura do diafragma e do tempo de exposição em f/20 e $(1 / 200)$ s, respectivamente. Na Figura 6 é possível observar o efeito da variação da sensibilidade ISO.
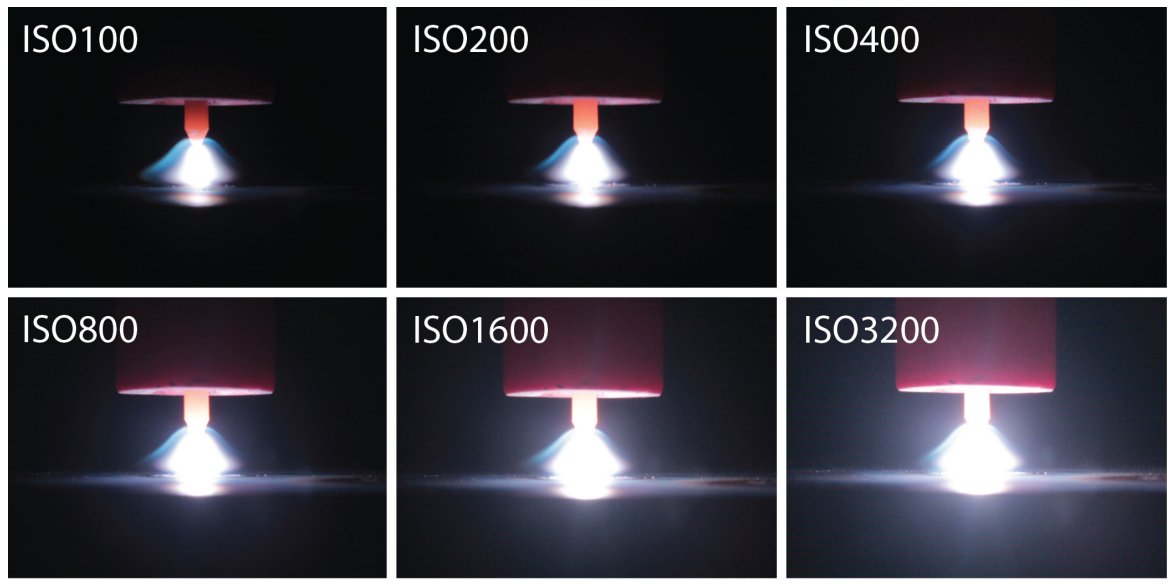

Figura 6. Imagens do arco voltaico obtidas com diferentes valores de sensibilidade ISO com abertura do diafragma e tempo de exposição fixos em f/20 e (1/200)s, respectivamente.

Com base nestes resultados, verifica-se que na obtenção de imagens do arco voltaico não é necessária a utilização de elevados valores de ISO, pois, conforme pode ser verificado, o aumento do mesmo resulta em imagens de maior luminosidade em detrimento da nitidez, o que não é necessário para obtenção de imagens do arco voltaico, visto que o mesmo é uma grande fonte luminosa.

\section{Filtro Densidade Neutra (ND)}

Nos ensaios anteriores foi utilizado o filtro ND 16, entretanto, é possível o emprego de filtros com diferentes graduações desde que a compensação da quantidade de luz que incide no sensor seja realizada nos parâmetros de exposição da câmera apresentados. Na Figura 7 são apresentadas imagens obtidas com filtros ND 16 e 8, tempo de exposição fixo em (1/200)s e diferentes ajustes de aberturas do diafragma. .
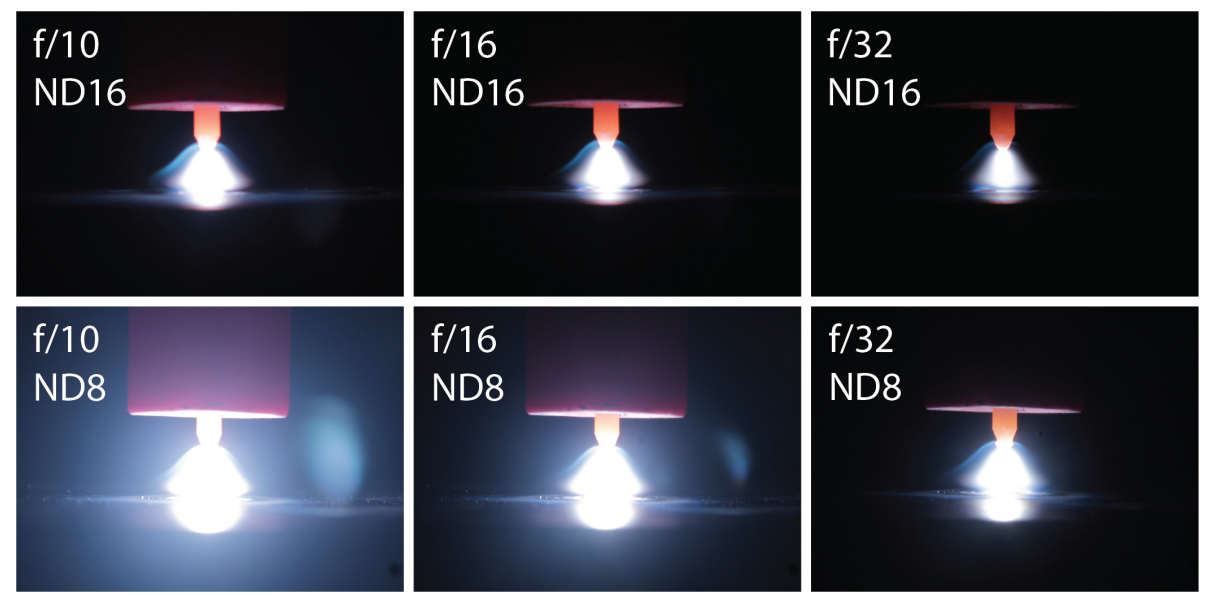

Figura 7. Variação do número-f no emprego do filtro ND 8 e 16. 
Conforme pode ser observado, foi obtido um resultado semelhante para a combinação f/10-ND 16 e com f/32-ND 8. De fato, como o filtro ND 8 permite a passagem de uma maior quantidade de luz do que o filtro ND 16, a imagem pode ser equilibrada ao ajustar o diâmetro de abertura do diafragma. Neste caso, visto que a lente utilizada possui um limite de fechamento do diafragma em f/36, não seria possível reduzir a luminosidade significativamente apenas alterando o número f. Logo, neste caso, seria necessário ajustar também um menor tempo de exposição.

\section{Corrente de Soldagem}

O emprego de diferentes correntes de soldagem, para uma mesma condição operacional, resulta em diferentes energias de soldagem. Um processo de maior energia, por sua vez, resulta num arco voltaico de maior intensidade luminosa [4]. Assim, pretendeu-se encontrar um conjunto de parâmetros de exposição que permita visualizar o arco em diferentes correntes de soldagem de interesse. Na Figura 8 é possível observar imagens do arco com correntes de soldagem de 50, 100 e 150A, obtidas com tempo de exposição de (1/200)s e diferentes aberturas do diafragma.
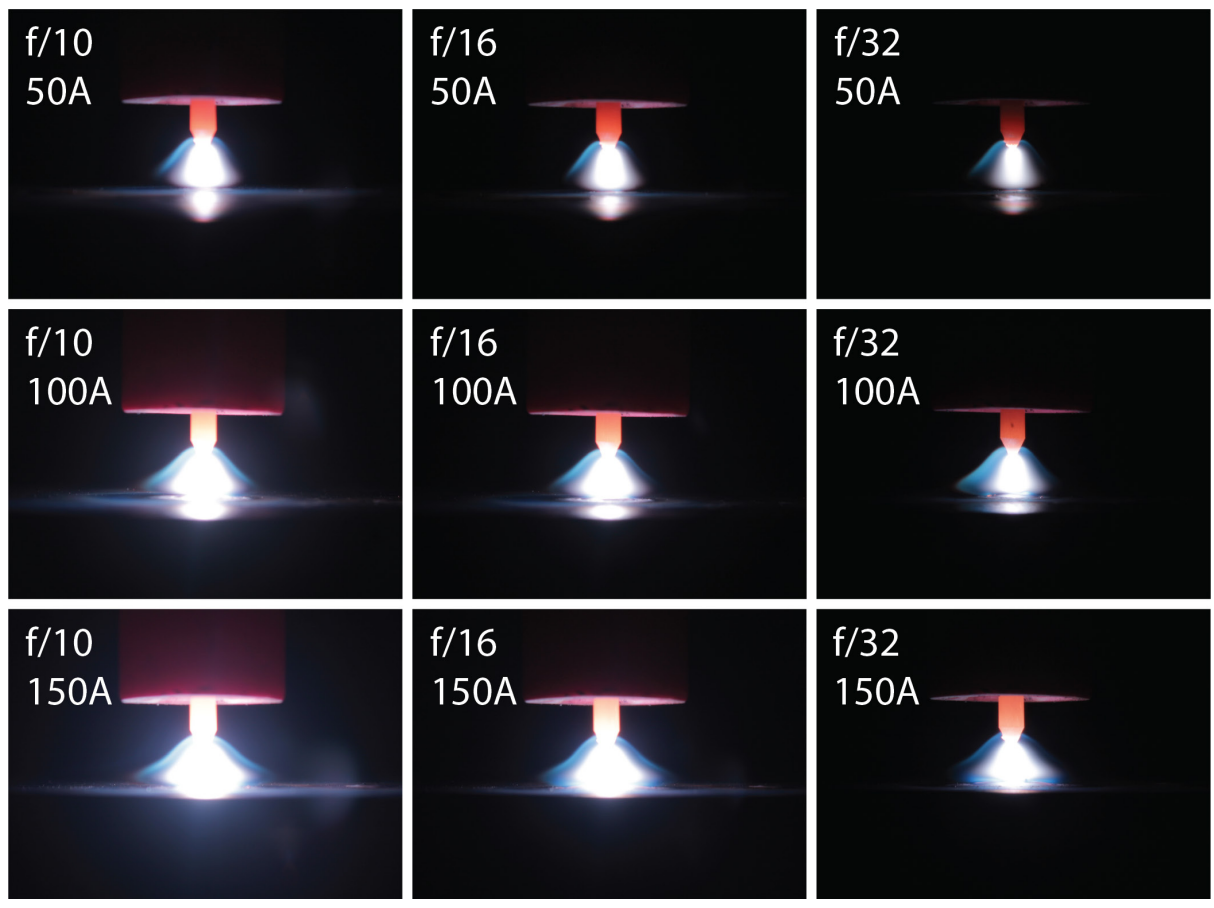

Figura 8. Imagens do arco voltaico com correntes de soldagem de 50, 100 e 150A obtidas com tempo de exposição de $(1 / 200)$ s e diferentes aberturas do diafragma.

Partindo do pressuposto que a imagem obtida com abertura do diafragma f/16 para a corrente de 100A seja a mais adequada à aplicação de interesse, neste caso, com esta configuração de exposição, obtém-se uma imagem saturada para a corrente de soldagem de 150A e uma intensidade reduzida de luminosidade para 50A. Buscando obter imagens similares em termos de luminosidade, a configuração com abertura do diafragma $\mathrm{f} / 32$ seria a mais adequada para a corrente de soldagem de 150A. De forma análoga, uma abertura do diafragma de f/10 para 50A. Ao empregar diferentes correntes de soldagem, faz-se necessário, portanto, o ajuste das configurações da câmera separadamente. Contudo, na utilização de corrente pulsada - em baixa frequência -, a corrente de soldagem transita entre dois patamares distintos de luminosidade do arco. Para este tipo de aplicação, cabe, portanto, ao pesquisador o ajuste dos parâmetros de exposição de modo que a posição de interesse (pulso ou base) seja evidenciada. É possível, não obstante, o registro em uma configuração de exposição intermediária, ou então, como alternativa, a realização de dois conjuntos de aquisições. Em um conjunto, os parâmetros de exposição seriam ajustados com o foco no período de pulso da corrente de soldagem e, em um segundo conjunto, no período de base. 
É importante salientar que, com essa solução de registro de imagens do arco, duas condições distintas de corrente de soldagem podem resultar em imagens do arco semelhantes, a exemplo das imagens da Figura 6 100A-f/16 e 150A-f/32. Para uma comparação qualitativa, portanto, é necessário fixar os parâmetros de exposição, permitindo, assim, visualizar as alterações no arco voltaico decorrentes das diferentes condições de soldagem, ainda que limitadas ao espectro visível.

\section{Exemplo de Aplicação}

Nos ensaios anteriores foi utilizada a configuração " $A$ " de posicionamento da câmera em relação ao arco voltaico, contudo, se o objeto de interesse da imagem é a poça de fusão, esta configuração não é a mais favorável. Para tanto, a câmera fotográfica foi posicionada de modo que fosse possível visualizar não apenas o eletrodo e o arco voltaico, mas também a poça de fusão, conforme configuração " $B$ ". Nesta configuração, ao utilizar um ângulo de 15으, foi possível observar a poça de fusão e ainda visualizar o eletrodo. Este valor está de acordo com a literatura [5] que afirma que, com a intenção de visualizar o máximo possível dos elementos de uma soldagem (eletrodo, arco, poça, chapa e bocal), tende-se a trabalhar com ângulos de posicionamento menores em relação à peça, sendo assim desnecessário aumentar a altura da tocha e sair das condições operacionais normalmente utilizadas em soldagem.

Visto que foi obtido um resultado bastante favorável na configuração de posicionamento da câmera anterior (Figura 8) para uma abertura de diafragma de f/16, tempo de exposição de (1/200)s, ISO 100 e ND16 ao empregar uma corrente de soldagem de 100A, essas mesmas regulagens foram aplicadas para a configuração inclinada. $\mathrm{Na}$ Figura 9 é possível observar a diferença de abordagem da configuração anterior e a inclinada com ângulo de 15ㅇ.
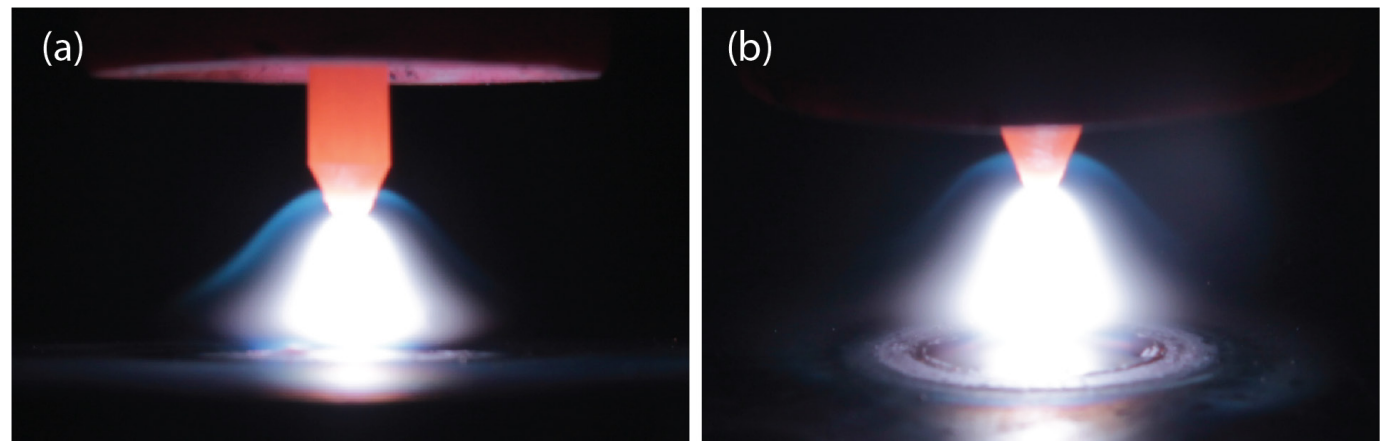

Figura 9. Imagem do arco voltaico para o posicionamento da câmera visando (a) avaliação dos parâmetros de regulagem da câmera e (b) visualização da poça de fusão.

O filtro polarizador circular (CPL) é utilizado por fotógrafos profissionais para reduzir reflexos, realçar cores e aumentar o contraste. No caso do registro do arco voltaico, o mesmo auxilia na redução dos reflexos produzidos pela intensa luminosidade do arco. Em especial, na peça de trabalho e na poça de fusão que, por vezes, pode dificultar a análise das imagens. Mantendo todos os parâmetros de exposição da câmera e soldagem fixos, foram realizadas duas imagens: uma sem filtro (Figura 10a) e outra com filtro CPL (Figura 10b).
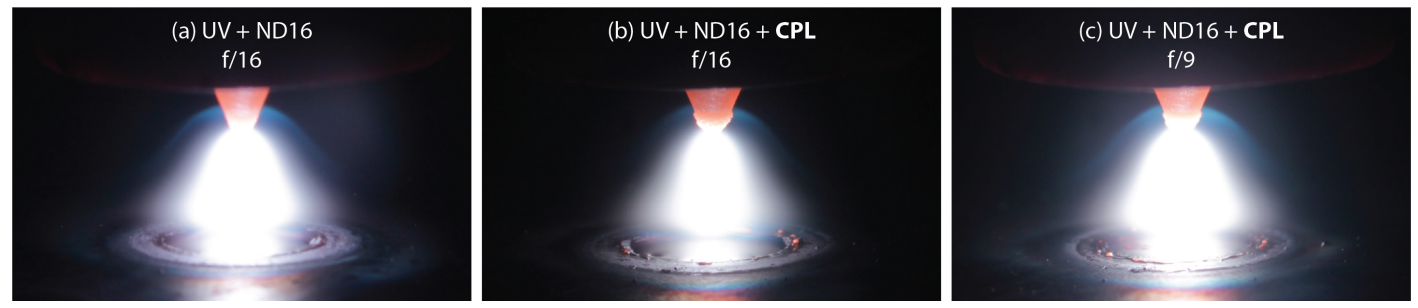

Figura 10. Comparativo entre imagem obtida (a) sem o filtro CPL e f/16, (b) com o filtro CPL para f/16 e (c) f/9. 
Como resultado é possível observar uma redução do reflexo produzido pelo do arco na peça de trabalho. Contudo, conforme pode ser observado, o filtro alterou sensivelmente a visualização do arco voltaico. Este efeito pode ser compensado alterando-se os parâmetros de exposição. Na Figura 10c é possível verificar que este efeito foi compensado por intermédio da abertura do diafragma, ou seja, do número-f. Desta forma, é possível concluir que a utilização dos filtros polarizadores CPL melhoram a nitidez da poça de fusão, apesar de interferirem no registro do arco.

Com os parâmetros de configuração da máquina da Figura 10c, foram realizadas imagens de uma soldagem utilizando o processo TIG com alimentação automática de arame. A corrente de soldagem utilizada foi a mesma dos ensaios anteriores (100A), assim como o comprimento livre do eletrodo e o DEP. A velocidade de soldagem empregada foi de $8 \mathrm{~cm} / \mathrm{min}$. A velocidade de alimentação do arame frio foi configurada de modo que fosse obtido uma transferência metálica por gotas, sendo que a mesma foi obtida a uma velocidade de 0,6 m/min. A câmera fotográfica foi utilizada no modo disparo contínuo, permitindo uma captura de, aproximadamente, 3 imagens por segundo. Na Figura 11 é apresentada uma sequência de imagens obtidas para essas configurações apresentadas.
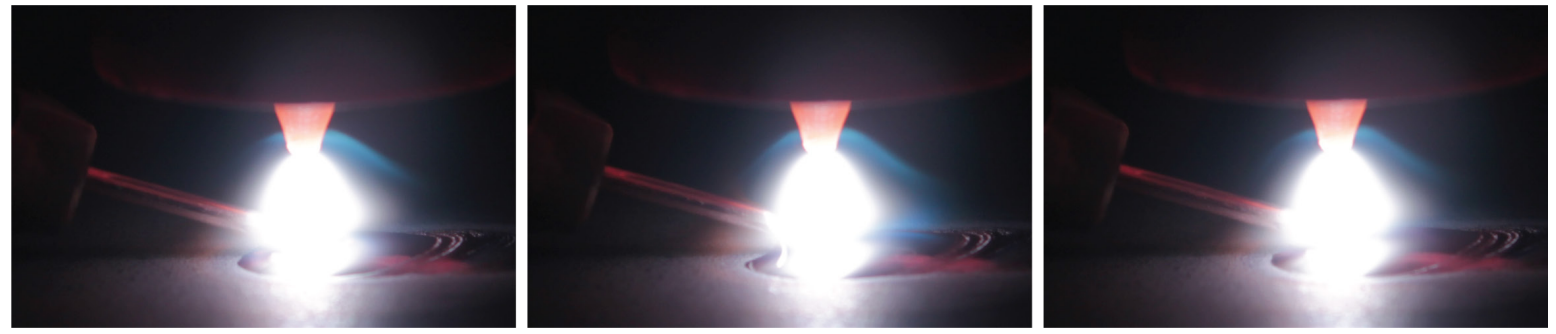

Figura 11. Sequência de imagens consecutivas obtidas com intervalos de tempo de (1/3)s na soldagem TIG com adição do arame utilizando parâmetros os mesmos parâmetros de exposição da Figura 10c.

Observa-se que apesar do arco voltaico, assim como, o dispositivo de alimentação do arame (bico de contato) e o próprio arame serem visíveis, não foi possível visualizar a transferência metálica. Portanto, a fim de diminuir a luminosidade com o intuito de permitir a visualização das gotas, foi diminuída a abertura do diafragma de f/9 para f/25. Na Figura 12 é apresentada a sequência de imagens obtidas após o ajuste da abertura do diafragma.
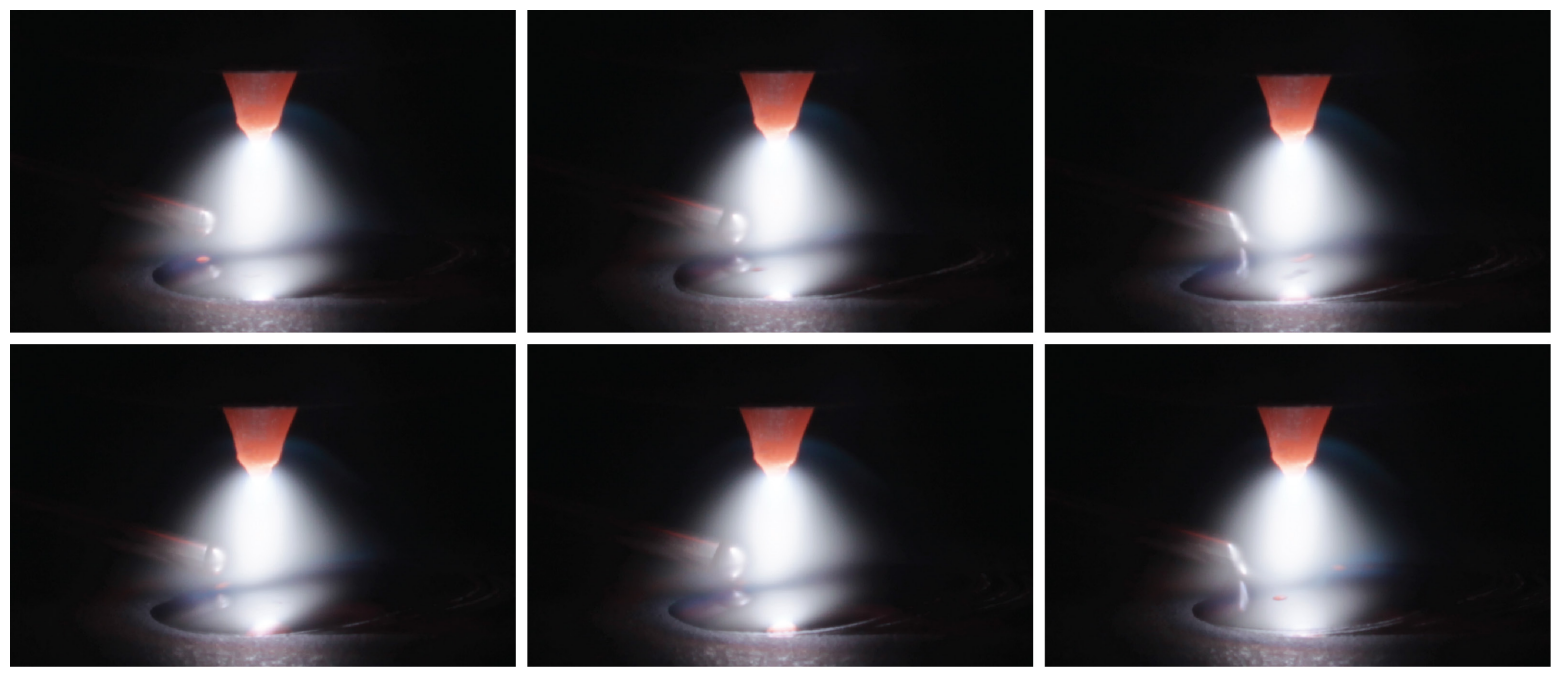

Figura 12. Sequência de imagens consecutivas obtidas com intervalos de tempo de (1/3)s na soldagem TIG com adição do arame utilizando parâmetros os mesmos parâmetros de exposição da Figura 11, porém, com f/25. 
Ao utilizar parâmetros de exposição que permitam uma menor passagem de luz, foi possível visualizar melhor a poça de fusão e a transferência metálica em detrimento do arame e bico de contato. Essa regulagem é interessante se, de fato, a transferência metálica e a poça de fusão são os objetos de interesse da imagem. Conforme discutido anteriormente, a regulagem dos parâmetros de exposição deve ser feita de modo que o fenômeno de interesse seja evidenciado. No caso de uma soldagem com TIG hot wire, por exemplo, em que o interesse é a visualização do possível sopro magnético causado no arco, uma regulagem próxima à Figura 11 seria a mais adequada.

Com o intuito de verificar as potencialidades da metodologia proposta no que diz respeito às possíveis alterações no arco voltaico, foi realizado o registro de um arco TIG estabelecido numa corrente de soldagem de 20A. Nestas condições, devido ao valor relativamente baixo da corrente de soldagem, o arco se apresentou relativamente instável. Deste modo, foi possível obter imagens sequenciais do arco voltaico, evidenciando tal comportamento. Na Figura 13 é apresentada a sequência de imagens obtidas nestas condições.
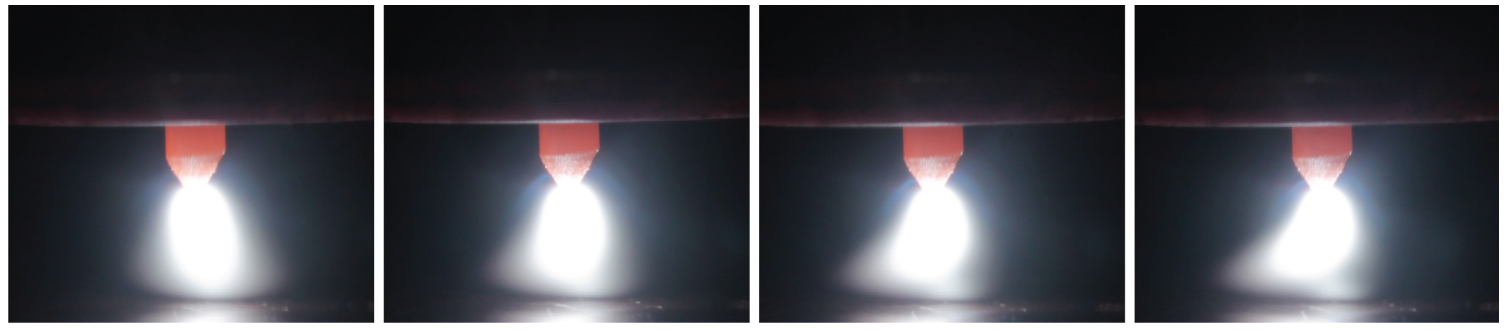

Figura 13. Sequência de imagens consecutivas obtidas com intervalos de tempo de (1/3)s na soldagem TIG com corrente de soldagem de $20 \mathrm{~A}$.

Muitas das limitações são decorrentes da capacidade da câmera e a escolha adequada dos filtros a serem utilizados. Câmeras que permitam a captura de um maior número de imagens por segundo no modo disparo contínuo possibilitam uma melhor caracterização dos fenômenos, sendo um fator importante na tomada de decisão da aquisição do equipamento, em especial, para análise da transferência metálica.

\section{Conclusões}

Com a realização deste trabalho foi possível concluir que:

- O registro de imagens do arco voltaico fazendo uso de uma câmera fotográfica comum, de relativo baixo custo, é viável desde que seja realizado o correto ajuste dos parâmetros de exposição (a câmera deve permitir o ajuste manual dos mesmos) e a utilização de filtros específicos;

- Através da análise do processo TIG com arame adicional frio, conclui-se que, para cada aplicação deve-se estudar a melhor configuração da câmera de modo que o fenômeno de interesse seja evidenciado;

- A utilização de filtros CPL e ND se apresentou essencial para uma melhor qualidade na obtenção das imagens, permitindo uma melhor visualização da poça e maior liberdade no ajuste dos parâmetros de exposição.

\section{Agradecimentos}

Os autores agradecem a POSMEC e ao CNPq, pelo apoio financeiro com o fornecimento da bolsa de pós-graduação. Agradecem também ao Laboratório de Tecnologia da Soldagem (UFSC-Joinville), ao LPS (Universidad de Antofagasta) e à empresa IMC Soldagem pelo auxílio no desenvolvimento deste trabalho.

\section{Referências}

[1] Langford M. Basic photography. 7th ed. Boca Raton: Taylor \& Francis; 2000. 343 p.
[2] Franco LDN. Sincronização, captura e análise de imagens da poça de soldagem no processo gmaw convencional, no modo 
de transferência metálica por curto-circuito [dissertação de mestrado]. Brasília: Universidade de Brasília; 2007.

[3] Mota CP. Sistema de visão por infravermelho próximo para monitoramento de processos de soldagem a arco [dissertação de mestrado]. Uberlândia: Programa de Pós-graduação em Engenharia Mecânica, Universidade Federal de Uberlândia.
[4] Modenesi PJ. Introdução à física do arco elétrico e sua aplicação na soldagem dos metais. Belo Horizonte: UFMG; 2007.

[5] Vilarinho LO, Lucas B, Raghunathan S. Cuidados ao se extrair dimensões de fotografia/filmagem em soldagem. Soldagem \& Inspeção. 2009;14(4):358-369. http://dx.doi.org/10.1590/ S0104-92242009000400011. 